\title{
Calculation of Dynamic Pore Pressure in Stone Column Composite Foundation*
}

\author{
H.R. Zhang ${ }^{1}$ and Y.M. Zhang ${ }^{1,2}$ \\ ${ }^{1}$ School of Civil Engineering and Architecture, Beijing Jiaotong University, Beijing 10044, \\ China \\ ${ }^{2}$ School of Storage and Transportation Engineering, China University of Petroleum - East \\ China, Dongying City, Shandong Province, Shandong 257061, China \\ hrzhang@163.com
}

\begin{abstract}
For typical initial and boundary conditions, a group of general solutions for the generation and dissipation of excess pore water pressure in stone column composite foundation under coupling action of dynamic and static loads have been developed by separation of variables and Green functions to the control differential equations. In the control equation, the pore pressure increasing ratio is expressed as the function of depth and time. A special solution is obtained to zero initial condition and upper boundary pervious, based on an existing dynamic pore pressure calculation model. The numerical example shows that the effect of seepage of the stone column is prominent.
\end{abstract}

Keywords: Stone Column; Pore Pressure; Dynamic; Drain; Liquefaction.

\section{Introduction}

The liquefaction of saturated sand generated by earthquake loading does tremendous damage to engineering structures. As one of anti-liquefaction reinforcement methods, stone column composite foundation has been widely used in engineering practice. In some cases, it may be the unique choice of foundation reinforcement strategy.

In order to understand the behavior of stone column composite foundation during earthquake, it is important to investigate the production, growth and dissipation of the pore water pressure in the sand deposit under the action of dynamic loads. The ordinary approach to deal with this problem is to adopt the Terzaghi's or Biot's consolidation theory, combined with a selected dynamic pore pressure models. For most of these approaches, numerical discretization is usually required in engineering applications. This may cost a great deal of computational effort. The alternative consideration is to seek analytical or semi-numerical computational methods. Some researchers have contributed to this problem.

\footnotetext{
* Supported by the National Natural Science Foundation of China (No. 50278003 \& 50678019).
} 
Seed \& Booker (1976) [1, 2] proposed a analytical solution for the dynamic pore water pressure formula to an asymmetric saturated sand model by combining Terzaghi's consolidation equations and a nonlinear increase model for pore water pressure induced by vibrations. The dissipation of water happens only in horizontal direction.

$\mathrm{Xu}$ (1985) [3] proposed a analytical solution to dynamic pore water pressure in saturated sand improved by stone columns, where the drainage occurs only in the radius direction. In 1992, $\mathrm{Xu}$ [4] extended his solutions to the situations where dissipation appears in both the horizontal (radius) and vertical directions and found that the vertical dissipation contributes a tremendous part in saturated sand during earthquake action.

Huang (1992) [5] proposed a simplified analytical solution in uniform strain condition with ignoring the well resistance of stone columns to the seepage.

In this paper, the solutions are extended to generalize pore water pressure model.

\section{Equations and Solutions}

It is assumed that the seepage of the porous water through sand is governed by the Darcy's law and the porous water is incompressible. The coefficient of permeability and the coefficient of compression of sand keep constant. The coefficient of permeability of stone column is large enough to neglect its resistance to seepage.

By the continuous condition of porous water flow, the control differential equation can be written in cylindrical coordinate system as following:

$$
\frac{\partial u}{\partial t}=C_{v r}\left(\frac{\partial^{2} u}{\partial r^{2}}+\frac{1}{r} \frac{\partial u}{\partial r}\right)+C_{v} \frac{\partial^{2} u}{\partial z^{2}}+\frac{\partial u_{g}}{\partial t} .
$$

Where $u$ is the excess pore pressure. $r$ is the distance from the center of stone column. $u_{g}$ is the dynamic pore pressure generated by vibrations. $C_{v r}$ and $C_{v}$ are the horizontal and vertical consolidation coefficients.

General solutions can be obtained by solving equation (1) by variable separation method and Green functions. When the initial pore water pressure is zero and only the upper boundary is free of drainage, the solutions for the generation and dissipation of excess pore water pressure in sand deposit improved by stone column can be expressed as following:

$$
u(r, z, t)=\sum_{n=0}^{\infty} \sum_{m=1}^{\infty} D_{m n} \sin \frac{(2 n+1) \pi}{2 H} z\left[J_{0}\left(v_{m} r\right)-\frac{J_{0}\left(v_{m} a\right)}{N_{0}\left(v_{m} a\right)} N_{0}\left(v_{m} r\right)\right] e^{-C_{v} \lambda_{m m} t} .
$$

In which, $v_{m}$ is the $m^{\text {th }}$ root of the following equation:

$$
J_{1}(v b) N_{0}(v a)-J_{0}(v a) N_{1}(v b)=0 .
$$


Where, $J_{0}(v a)$ and $J_{1}(v a)$ are the Bessel functions of the 1 st kind of order zero and 1st. $N_{0}(v a)$ and $N_{1}(v b)$ are the Bessel functions of the 2nd kind of order zero and 1 st.

$$
\begin{gathered}
D_{m n}=\int_{0}^{t} \int_{0}^{H} \frac{\partial u_{g}}{\partial t} \frac{2 \pi J_{1}^{2}\left(v_{m} b\right) N_{0}\left(v_{m} a\right) \sin \frac{(2 n+1) \pi}{2 H} \eta}{H\left[J_{1}^{2}\left(v_{m} b\right)-J_{0}^{2}\left(v_{m} a\right)\right]} e^{C_{v} \lambda_{m n} \tau} d \eta d \tau . \\
\lambda_{m n}=\frac{(2 n+1)^{2} \pi^{2}}{4 H^{2}}+\frac{C_{v r}}{C_{v}} v_{m}{ }^{2}, \quad n=1,2 \cdots ; m=1,2 \cdots .
\end{gathered}
$$

It can be found that the solution form depends on the dynamic pore water pressure model of $u_{g}$. To illustrate the principal behavior of stone columns, the following dynamic pore water pressure model [6] is adopted:

$$
u_{g}=u_{f}\left[\frac{1}{2}\left(1-\cos \pi \frac{t}{t_{f}}\right)\right]^{B}=A_{0} \gamma^{\prime} z\left[\frac{1}{2}\left(1-\cos \pi \frac{t}{t_{f}}\right)\right]^{B} .
$$

In which, $u_{f}$ is the possible maximum pore pressure. $t_{f}$ is the time to reach $u_{f} . B$ and $A_{0}$ are parameters.

\section{Numerical Example}

A site is composed of silty sand of $8 \mathrm{~m}$ thick. The diameter and space of the stone column are $0.6 \mathrm{~m}$ and $2.0 \mathrm{~m}$ separately. The other parameters are shown in Table 1.

Table 1. Parameters

\begin{tabular}{ccccccccc}
\hline Parameter & $\gamma\left(\mathrm{kN} / \mathrm{m}^{3}\right)$ & $k_{h}(\mathrm{~m} / \mathrm{s})$ & $k_{v}(\mathrm{~m} / \mathrm{s})$ & $m_{v}\left(\mathrm{kPa}^{-1}\right)$ & $K_{0}$ & $\phi^{\prime}\left({ }^{\circ}\right)$ & $B$ & $A_{0}$ \\
\hline Value & 19.0 & $10^{-5}$ & $4 \times 10^{-6}$ & $1.5 \times 10^{-4}$ & 0.5 & 36.6 & 2 & 1.25 \\
\hline
\end{tabular}

Substituting equation (6) into (5), special solution can be obtained and the numerical results are shown in Fig. 1 to Fig. 4.

It is shown from these figures that the maximum pore pressure occurs in the intermediate depth (Fig. 1). The pore pressure decreases with closing to the column in depth of $1 \mathrm{~m}$ and $5 \mathrm{~m}$ (Fig.2 and 3). The effect of stone column decreases with depth in the conditions that only upper boundary is free of drainage (Fig.4). 


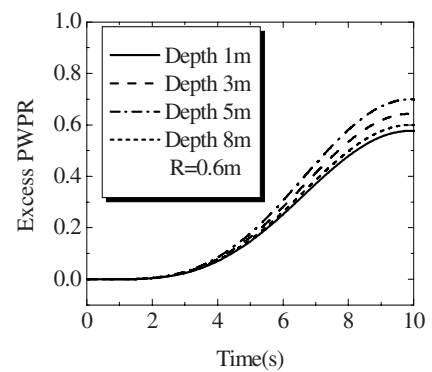

Fig. 1.The Pore pressure development in sand deposit with stone column drainage

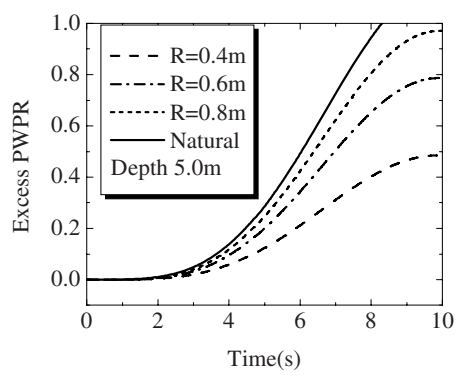

Fig. 3. The Pore water pressure ratio change with distance from the stone column at depth $5.0 \mathrm{~m}$.

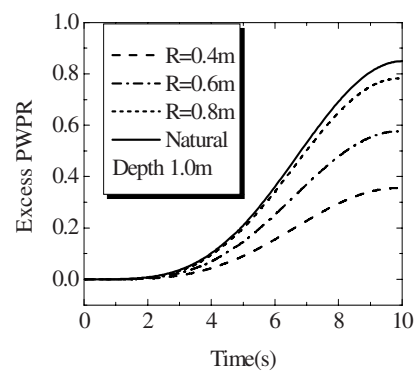

Fig. 2.The Pore pressure ratio change with distance from the stone column at depth $1.0 \mathrm{~m}$.

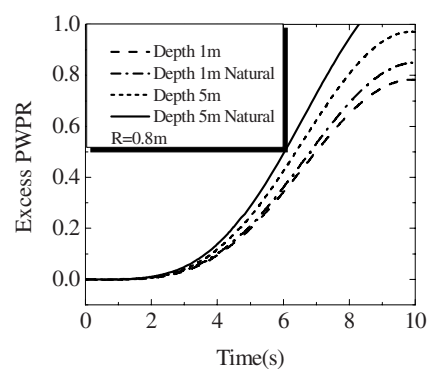

Fig. 4. The Pore water pressure ratio change with depth at distance $0.8 \mathrm{~m}$

\section{Conclusions}

The effect of seepage of the stone column is prominent. The maximum pore pressure occurs in the intermediate depth. The excess pore pressure increases with the distance to the stone column. The effects of stone column decrease with depth when the lower boundary is impervious.

\section{References}

1. Seed, H. B. \& Booker, J. R.: Stabilization of Potentially Liquefiable Sand Deposits Using Gravel Drains Systems. Report No. EERC 76-10, University of California, Berkeley. (1976)

2. Seed, H.B. \& Booker, J. R.: Stabilization of Potentially Liquefiable Sand Deposits Using Gravel Drains. J. of Geotechnical Engineering Division, ASCE, 103(GT7) (1977) 757-768

3. $\mathrm{Xu}, \mathrm{Z}$. Y.: Anti-liquefaction Analysis and Calculation of Sand Deposits Using Gravel Drains, Survey Science and Technology, 1 (1985)1-7

4. Xu, Z. Y.: Calculation of Pore Pressure of Liquefiable Sand Deposits Using Gravel Drains, Earthquake Engineering and Engineering Vibration, Vol. 12, No. 4 (1992)88-93 
5. Huang, M. S., Wu, S. M. \& Zhao, Z. Z.: Liquefaction Analysis of Subsoil Strengthen by Vibro-flotion Stone Pile Method and Vibro-compaction Sand Pile Method, Journal of Zhejiang University, Vol. 26, No. 2 (1992) 165-171

6. Zhang, J. M. \& Xie, D. Y.: A Practical Calculation Method for the Growth of Vibration Induced Pore Pressure in Saturated Sand. Journal of Hydraulics, 8 (1989)45-51 